\title{
The role of hormonal treatment in type 2 diabetes mellitus
}

This article was published in the following Dove Press journal:

Research and Reports in Endocrine Disorders

12 February 2015

Number of times this article has been viewed

\section{Syed Khalid Imam}

Liaquat National Hospital and Medical College, Karachi, Pakistan; Al-Mouwasat Hospital, Jubail Industrial City, Kingdom of Saudi Arabia
Correspondence: Syed Khalid Imam Al-Mouwasat Hospital, Jubail Industrial City, Kingdom of Saudi Arabia Tel +966566808703

Email docimam@yahoo.com
Abstract: Diabetes mellitus (DM) is a disorder of abnormal glucose metabolism resulting primarily from insulin resistance and relative insulin deficiency and characterized by hyperglycemia causing significant short- and long-term complications. Type 2 diabetes mellitus (T2DM) contributes to more than $90 \%$ of cases of diabetes. Obesity, sedentary lifestyles, and consumption of very high-caloric meals are thought to be the primary triggering factors causing T2DM in genetically predisposed individuals. Although treatment of hyperglycemia plays a key role in the management, therapies directed at other comorbid conditions, such as dyslipidemia, hypertension, hypercoagulability, obesity, and insulin resistance, have also been a major focus of research and therapy. DM is rising to an epidemic proportion globally, and it is, indeed, one of the most challenging public health problems in the 21 st century. According to 2011 statistics, there were approximately 366 million diabetes cases worldwide, and this figure would probably increase to 552 million by 2030. Long-term complications from high blood sugar include coronary artery disease, cerebrovascular events, peripheral arterial diseases leading to amputation, retinopathy, nephropathy leading to end-stage renal disease requiring hemodialysis and transplantation, and neuropathy. The acute complication of T2DM includes drug-induced hypoglycemia, hyperosmolar hyperglycemic state, and although uncommon, ketoacidosis. Diabetes care requires a comprehensive and multidisciplinary approach to delay the progression to acute as well as chronic and debilitating long-term complications. This approach requires the thorough understanding of the pathophysiology of hyperglycemia and impact of various risk factors and comorbidities, careful selection of antihyperglycemic agents, active and frequent participation of diabetes educator, and involvement of multidisciplinary team. The objective of this review is to highlight recent trends in hormonal treatment and to explore new and innovative therapeutic modalities in the management of T2DM.

Keywords: diabetes mellitus, hormonal treatment, early insulinization, glycosylated hemoglobin, ketoacidosis, hyperglycemia, hypoglycemia

\section{Introduction}

Diabetes mellitus (DM) is a chronic metabolic illness causing significant morbidity and mortality resulting from acute and long-term macrovascular and microvascular complications. The approach to diabetes care clearly requires the thorough understanding of the pathophysiology of hyperglycemia and impact of various risk factors and comorbidities, careful selection of antihyperglycemic agents, active and frequent participation of diabetes educator, and involvement of multiple specialty teams. ${ }^{1}$ Though we know that aggressive treatment of hyperglycemia is central to diabetes management, we should also address and treat the various risk factors and comorbid conditions such as obesity, smoking, hypertension, dyslipidemia, and hypercoagulability states. 
The global prevalence of diabetes is now quoted to be $8.3 \%$. North America and Caribbean bear the higher prevalence $(11 \%)$, while in the Middle East and North Africa, the prevalence is found to be $9.2 \%$.

India, People's Republic of China, and the US are the top three countries in the number of people with diabetes, and it is predicted that Africa would sustain the highest burden in the next 20 years. ${ }^{2}$

According to the International Diabetes Federation statistics, the number of people living with diabetes will increase to 552 million by 2030 , meaning that DM is rising to an epidemic proportion globally and it is, indeed, one of the most challenging public health problems in the 21 st century. People with impaired glucose tolerance are mostly asymptomatic but do carry an increased risk of coronary artery disease. Obesity and sedentary lifestyles are the key elements in the rapid progression of type 2 diabetes mellitus (T2DM), contributing to as much as $90 \%$ burden of diabetes. ${ }^{3}$

There are many barriers in the successful management of diabetes such as cost, genetic interplay, environmental factors, and comorbid conditions. ${ }^{4}$ Vast majorities of T2DM patients do not achieve the target glycemic control, and only one third of them meet the targets for good glycemic control, optimum blood pressure, and cholesterol control. ${ }^{5}$

It is evident from the Diabetes Complications and Control Trial (DCCT) and the Epidemiology of Diabetes Interventions and Complications (EDIC) trial that early intervention to control hyperglycemia may significantly retard the progression to the long-term diabetes complications. ${ }^{6,7}$

The cost of diabetes management is enormous. It is estimated that in 2007, the total cost of diabetes treatment was 174 billion US dollars. The emergency treatment and average medical expenditures in diabetics are almost twice that of nondiabetics. ${ }^{8,9}$

The objectives of this review are to provide a brief overview on nonhormonal therapy, to present the pros and cons of nonhormonal oral antidiabetes medications and highlight newer trends in the hormonal treatment, and to explore the innovative and newest therapeutic modalities in the management of T2DM.

\section{Pitfalls of nonhormonal treatment: a brief overview}

There are many challenges in diabetes management, and majority of T2DM diabetics generally start with oral medications to control hyperglycemia. Oral antihyperglycemic drugs require close observation for dose titration as well as side effects resulting from such medications. Patients must also be counseled and taught about the drug usage, possible side effects, dose titration, and self-care management. Frequent self-monitoring of blood glucose must be encouraged, and patients must be educated to limit the consumption of highcalorie food and beverages.

There are seven types of nonhormonal antihyperglycemic drugs currently approved for the treatment of diabetes: biguanides, sulfonylureas, meglitinides, glitazones, alpha-glucosidase inhibitors (AGIs), dipeptidyl peptidase-4 (DPP-4) inhibitors, and sodium-glucose co-transporter inhibitors. Tables 1 and 2 present the classification of nonhormonal antidiabetes therapeutic agents and potential side effects of these agents, respectively.

\section{Biguanides}

Metformin is the most widely used first-line oral nonhormonal therapy and especially recommended for obese T2DM. Common side effects are gastrointestinal related, which may

Table I Classification of nonhormonal antihyperglycemic agents

\begin{tabular}{|c|c|}
\hline Antidiabetic agents & Basic mechanism \\
\hline \multicolumn{2}{|l|}{ Insulin sensitizers } \\
\hline \multicolumn{2}{|l|}{ Biguanides } \\
\hline \multirow[t]{5}{*}{ Metformin } & Activation of adenosine \\
\hline & monophosphate kinase \\
\hline & Inhibition of gluconeogenesis \\
\hline & Increase insulin sensitivity \\
\hline & Improve beta-cell function \\
\hline \multicolumn{2}{|l|}{ Thiazolidinediones } \\
\hline \multirow[t]{6}{*}{ Pioglitazone, rosiglitazone } & Activation of PPAR- $\gamma$ \\
\hline & Increase glucose transporter \\
\hline & expression (GLUT I and GLUT 4) \\
\hline & Decrease gluconeogenesis \\
\hline & Increase differentiation of \\
\hline & preadipocytes into adipocytes \\
\hline \multicolumn{2}{|l|}{ Insulin secretagogues } \\
\hline \multicolumn{2}{|l|}{ Sulfonylureas } \\
\hline $\begin{array}{l}\text { Gliclazide, glimepiride, glipizide, } \\
\text { glibenclamide (glyburide) }\end{array}$ & $\begin{array}{l}\text { Stimulate insulin release from } \\
\text { pancreatic beta cells by inhibiting }\end{array}$ \\
\hline Non-sulfonylureas & potassium ATP channels \\
\hline \multicolumn{2}{|l|}{ Repaglinide, nateglinide } \\
\hline \multicolumn{2}{|l|}{ Alpha-glucosidase inhibitors } \\
\hline \multirow[t]{3}{*}{ Acarbose } & Inhibition of disaccharidase \\
\hline & Delay conversion of disaccharides \\
\hline & in to monosaccharide \\
\hline \multicolumn{2}{|l|}{ DPP-4 inhibitors } \\
\hline \multirow{4}{*}{$\begin{array}{l}\text { Sitagliptin, vildagliptin, saxagliptin, } \\
\text { linagliptin, alogliptin }\end{array}$} & Decrease glucagon release \\
\hline & Glucose-dependent insulin release \\
\hline & Decrease appetite \\
\hline & Delay gastric emptying \\
\hline \multicolumn{2}{|c|}{ Sodium-glucose co-transporter 2 (SGLT2) inhibitors } \\
\hline \multirow{3}{*}{$\begin{array}{l}\text { Canagliflozin, dapagliflozin, } \\
\text { empagliflozin }\end{array}$} & Inhibit reabsorption of glucose \\
\hline & from proximal convoluted tubules \\
\hline & and promote glycosuria \\
\hline
\end{tabular}

Abbreviations: PPAR- $\gamma$, peroxisome proliferator-activated receptor gamma; DPP-4, dipeptidyl peptidase-4. 
Table 2 Drawbacks of nonhormonal treatment

\begin{tabular}{|c|c|c|}
\hline Antidiabetic agents & Potential side effects & Limitations to usage \\
\hline \multicolumn{3}{|l|}{ Insulin sensitizers } \\
\hline Biguanides & $\begin{array}{l}\text { Gastrointestinal disturbance, lactic acidosis, } \\
\text { and } \mathrm{B} / 2 \text { deficiency }\end{array}$ & $\begin{array}{l}\text { Chronic kidney diseases, chronic liver diseases, } \\
\text { pulmonary insufficiency, and congestive cardiac failure }\end{array}$ \\
\hline Thiazolidinedione & $\begin{array}{l}\text { Peripheral edema, dilutional anemia, and atypical } \\
\text { fractures }\end{array}$ & $\begin{array}{l}\text { Congestive heart failure, renal failure, risk factors of } \\
\text { bladder cancer, pregnancy, and lactation }\end{array}$ \\
\hline \multicolumn{3}{|l|}{ Insulin secretagogues } \\
\hline Sulfonylureas & Allergy, weight gain, and hypoglycemia & $\begin{array}{l}\text { Renal failure, hepatic failure, porphyria, pregnancy, } \\
\text { and lactation }\end{array}$ \\
\hline Non-sulfonylureas & Weight gain and hypoglycemia & Liver diseases, pregnancy, and lactation \\
\hline $\begin{array}{l}\text { Alpha-glucosidase } \\
\text { inhibitors }\end{array}$ & Flatulence, diarrhea, and abdominal pain & $\begin{array}{l}\text { Inflammatory bowel disease, renal and liver diseases, } \\
\text { pregnancy, and lactation }\end{array}$ \\
\hline $\begin{array}{l}\text { Dipeptidyl peptidase- } 4 \\
\text { inhibitors }\end{array}$ & $\begin{array}{l}\text { Nausea, vomiting, diarrhea, nasopharyngitis, } \\
\text { and pancreatitis }\end{array}$ & $\begin{array}{l}\text { Hypersensitivity reaction, history of pancreatitis, and } \\
\text { renal failure }\end{array}$ \\
\hline $\begin{array}{l}\text { Sodium-glucose co- } \\
\text { transporter } 2 \text { inhibitors }\end{array}$ & $\begin{array}{l}\text { Urinary tract infections, genital mycotic infections, } \\
\text { polyurea, hypotension, hyperkalemia, increased } \\
\text { LDL cholesterol, and cardiovascular side effects }\end{array}$ & Renal diseases, pregnancy, and lactation \\
\hline
\end{tabular}

Abbreviation: LDL, low-density lipoprotein.

result in withdrawal of drug in $20 \%-30 \%$ of cases. Rarely, it may result in lactic acidosis, medical condition with a high mortality rate, if used in certain medical conditions such as renal failure, acute illnesses, dehydration, and respiratory insufficiency. ${ }^{10}$ Therefore, patient must be educated to withhold the drug in case of acute illness and dehydration status, and while undergoing surgical procedures and receiving intravenous contrast agents.

\section{Insulin secretagogues}

Insulin secretagogues such as sulfonylureas (glyburide, glipizide, glimepiride) and meglitinides (nateglinide and repaglinide) stimulate insulin release from beta cells and can produce hypoglycemia as a side effect, especially in the event of fasting and missed meals.

The onset of action of sulfonylureas is slow, and dosage is difficult to titrate acutely, and some of the agents of this class also have a prolonged duration of action causing great difficulties in the event of hypoglycemia. With the passage of time, majority of T2DM patients develop secondary failure and poor glycemic control because of progressive loss of pancreatic beta cells. ${ }^{11}$

Meglitinide is a non-sulfonylurea moiety and a weak oral antihyperglycemic agent, which may be used in patients with allergy to sulfonylurea and renal failure. ${ }^{12}$

Side effects are similar to sulfonylureas, but incidence of hypoglycemia is less commonly reported.

\section{Thiazolidinedione}

The first drug of this class, troglitazone, was withdrawn from the market because of fatal hepatotoxicity. Pioglitazone and rosiglitazone are the drugs of this class currently available. They increase insulin sensitivity through a complex mechanism and are indicated in T2DM in combination with other oral agents. ${ }^{13}$

They also exhibit the potential side effects of liver dysfunction, significant weight gain, anemia, and decreased bone density causing increased fracture risk at atypical sites like forearm..$^{14,15}$

\section{Alpha-glucosidase inhibitors}

AGIs act by inhibiting disaccharidase, an enzyme that breaks down disaccharides to monosaccharides in the intestinal brush border and decreases postprandial glucose excursion. ${ }^{16}$

Gastrointestinal side effects are frequent and include abdominal bloating, flatulence, and cramping. Because of these common side effects, most of the patients are unable to tolerate and stop taking medicine.

\section{DPP-4 inhibitors}

DDP-4 inhibitors stimulate glucose-dependent insulin release from beta cells, decrease glucagon secretion, and suppress hepatic gluconeogenesis. It has also been suggested from animal studies that DPP-4 inhibitors enhance survival of pancreatic beta cells by inhibiting apoptosis, a process of natural cell decay. ${ }^{17}$ This phenomenon should also be explored in humans as a potential treatment to preserve beta-cell function.

These agents can be used as monotherapy or in combination with other oral drugs and insulin. Common side effects are anorexia, nausea, abdominal pain, and vomiting. Few cases 
of acute pancreatitis have also been reported with the use of sitagliptin, but clinical trials are yet to confirm the definite association of acute pancreatitis and use of DPP-4 inhibitors. ${ }^{18,19}$

\section{Sodium-glucose co-transporter (SGLT2) inhibitors}

Sodium-dependent glucose co-transporters (or sodiumglucose-linked transporter 2, SGLT2) are a family of glucose transporters expressed in the proximal convoluted tubules from where $90 \%$ of the glucose is absorbed. Canagliflozin, dapagliflozin, and empagliflozin are currently available drugs in this class. ${ }^{20-22}$

Common side effects include urinary tract infections and genital mycotic infections and are associated with increased urination and episodes of hypotension and hyperkalemia.

\section{Nonhormonal treatment and cardiovascular safety}

- Biguanides are frequently associated with gastrointestinal disturbances such as nausea, vomiting, and diarrhea. Chronic metformin treatment is likely to be associated with vitamin B12 deficiency because of decreased absorption. B12 deficiency may lead to hyperhomocysteinemia, which is an established risk factor for cardiovascular disease. However, metformin is the first-line antihyperglycemic agent used as monotherapy as well as in combination with other oral and injectable agents. Overall, clinical trials have shown its long-term safety in cardiovascular diseases. ${ }^{23-25}$

- Sulfonylureas may worsen myocardial ischemia due to halting of ischemic preconditioning by inhibiting the hyperpolarization state, which blocks the calcium influx and protects the myocardium from further damage. The University Group Diabetes Program study has shown the link between use of sulfonylurea and incidence of cardiovascular event and mortality. ${ }^{26}$ However, this association has not been substantiated by the UK Prospective Diabetes Study (UKPDS) or Action in Diabetes and Vascular Disease: Preterax and Diamicron MR Controlled Evaluation (ADVANCE) study. ${ }^{27,28}$

Among sulfonylureas, the use of glyburide was associated with highest mortality (7.5\%) compared to gliclazide and glimepiride (2.7\%). ${ }^{29}$ However, the cardiovascular safety of sulfonylureas cannot be considered established unless it is evaluated in long-term cardiovascular outcomes trials. ${ }^{30}$ It is assumed that meglitinides may appear to exert similar cardiovascular profile, but there is not enough data available to support this hypothesis.
- Rosiglitazone and pioglitazone are the available thiazolidinediones. Meta-analyses of randomized controlled trials have shown an increased risk of fatal and nonfatal myocardial infarctions with rosiglitazone. ${ }^{31} \mathrm{In}$ contrast, meta-analysis of trials of pioglitazone indicates the beneficial effect on overall cardiovascular outcomes. ${ }^{32}$ Peripheral and pulmonary edema have been reported in a number of cases; therefore, these drugs are contraindicated in diabetics with New York Heart Association (NYHA) class III or IV cardiac failure.

- AGIs: No long-term data are available to disclose the cardiovascular outcomes. However, the Study to Prevent Noninsulin-Dependent Diabetes Mellitus (STOP NIDDM) trial showed a marked reduction in fatal cardiovascular events in high-risk individual with impaired glucose tolerance. ${ }^{33}$

- As a matter of fact, DPP-4 inhibitors improve several cardiovascular risk factors. They improve postprandial glucose control, are weight neutral, may lower blood pressure, improve postprandial and fasting lipemia, and reduce inflammatory markers in patients with T2DM. In addition, positive effects on the myocardium have been described in patients with ischemic heart disease. ${ }^{34}$

- Sodium-glucose co-transporter 2 inhibitors are the latest addition to oral therapy. There is evidence from one study that adding dapagliflozin to currently available treatment regimen is likely to decrease the macrovascular and microvascular complications associated with T2DM. ${ }^{35}$

It is quite evident that many oral antidiabetes drugs are associated with cardiovascular and non-cardiovascular hazards, cannot be titrated acutely, and have limitations of usage in special circumstances. ${ }^{36}$ Therefore, nonhormonal antihyperglycemic pharmacological approaches should be further evaluated in randomized clinical trials for patients' benefit and safety.

\section{Hormonal treatment}

Insulin is the oldest and the most effective currently available hormonal treatment indicated for all types of diabetes. Table 3 presents the classification and pharmacokinetic profiles of insulin. It is the most extensively studied hormone and was discovered in 1921 by Frederick G Banting and John Macleod, the winners of Nobel Prize in 1923. Leonard Thompson, a teenager with diabetes, became the first person to receive insulin shot in 1922 and improved drastically after receiving insulin.

Other relatively new hormonal treatment for T2DM includes incretin mimetic such as glucagon-like peptide-1 (GLP-1) analog and amylin analog. 
Table 3 Classification and pharmacokinetic profiles of insulin

\begin{tabular}{llll}
\hline Insulin types & Onset & Peak & $\begin{array}{l}\text { Duration } \\
\text { of action }\end{array}$ \\
\hline $\begin{array}{l}\text { Conventional insulin } \\
\text { Short-acting regular }\end{array}$ & $30-60$ minutes & 2 hours & 6 hours \\
$\begin{array}{l}\text { Intermediate-acting } \\
\text { Analogs }\end{array}$ & $2-4$ hours & $4-6$ hours & 18 hours \\
$\begin{array}{l}\text { Ultra-short-acting } \\
\text { Lispro }\end{array}$ & $5-15$ minutes & 60 minutes & 2 hours \\
$\begin{array}{l}\text { Aspart } \\
\text { Glulisine }\end{array}$ & $5-15$ minutes & 60 minutes & 2 hours \\
Long-acting & $5-15$ minutes & 60 minutes & 2 hours \\
$\begin{array}{l}\text { Glargine } \\
\text { Detemir }\end{array}$ & $2-4$ hours & Not significant & 24 hours \\
& $2-4$ hours & Not significant & 20 hours \\
\hline
\end{tabular}

\section{Insulin therapy in T2DM}

Table 3 presents the classification and pharmacokinetics of insulin.

\section{Insulin deficiency and T2DM}

Insulin resistance and beta-cell dysfunctions are the hallmarks of the pathophysiology of T2DM reported to be present in $90 \%$ and $50 \%$ of cases, respectively, in genetically predisposed individuals. This scenario is further complicated by the progressive beta-cell loss, which is augmented by glucolipotoxicity, increased islet amyloid deposition, and inflammatory cytokines. ${ }^{37-39}$ These effects lead to decreased first-phase insulin release, later followed by impaired second-phase insulin release. No matter how good is glycemic control, a fall in beta-cell function and mass is the rule with the passage of time. However, accelerated deterioration in beta-cell mass was observed in those with poor glycemic control. Therefore, patients with longer duration of diabetes need dose increment and add-on therapy.

Patients can benefit from insulin therapy at some point after diagnosis, since it is estimated that beta-cell mass reduces by $4 \%$ per year. One study conducted in the US population revealed that only $12 \%$ of T2DM patients were taking insulin, whereas $14 \%$ were taking both insulin and oral medication. ${ }^{40}$

Insulin is an absolute requirement for type 1 (T1) diabetes, and many patients with T2DM will eventually require insulin as their beta-cell function declines over time. To achieve normoglycemia, insulin therapy should begin with lifestyle modification and weight reduction and requires consistency to maintain euglycemic state.

Main objective of normoglycemia is to prevent acute and chronic diabetes-related complications, and previously conducted randomized trials only showed that insulin therapy reduced microvascular complications. ${ }^{28,41}$ In fact, recent follow-up data from the UKPDS conclude that early insulinization also reduces macrovascular complication in T2DM. ${ }^{42}$

After availability of newer therapeutic modalities and newer insulin analogs, physicians may find difficulty in selecting the best therapeutic regimen for their patients. However, each patient must be individualized for a particular treatment modality. New guidelines on diabetes management may also help determine which treatment should be started first and how to initiate and titrate insulin dosage to get optimum glycemic targets. ${ }^{43,44}$

\section{Glycemic targets for T2DM patients}

Achieving good glycemic targets is an essential requirement to prevent and delay the diabetes-related complications, and many large randomized clinical trials have shown that achieving glycosylated hemoglobin $\left(\mathrm{HbA}_{1 \mathrm{c}}\right.$ ) below $7 \%$ reduces microvascular complications in T2DM..$^{28,45-47}$ These trials initially indicated microvascular risk reduction, and 10-year follow-up UKPDS also showed cardiovascular risk reduction after lowering $\mathrm{HbA}_{1 \mathrm{c}}$ below $7 \%$ in intensively treated groups. ${ }^{43}$

Since complications from chronic hyperglycemia take several years to develop, tighter glycemic control should be reserved to those with prolonged life expectancy, young individuals, and those without vital organ dysfunctions. The American Diabetes Association guidelines recommend the following glycemic targets for T2DM:

- $\mathrm{HbA}_{1 \mathrm{c}} 7 \%$ or less

- Preprandial plasma glucose levels of 70-130 mg/dL

- 2-hour postprandial glucose levels of less than $180 \mathrm{mg} / \mathrm{dL}$. As per these guidelines, glycemic targets should be individualized, and flexible and less tighter glycemic targets (7\%-8\%) should be considered for those at higher risk of hypoglycemia and can be categorized as follows.

- Elderly T2DM

- Advanced microvascular complications

- Severe macrovascular complications

- Shorter life expectancy

- Known epilepsy

- Recurrent history of hypoglycemia.

\section{Insulin initiation: a challenge to health care providers} Insulin initiation remains a challenge to health care providers, although it is the most effective means to achieve euglycemia, and its initiation requires a thorough counseling, education time, and effort from health care providers. ${ }^{48,49}$ 
Patient resistance to the use of insulin is one of the barriers to initiate insulin therapy and especially prevails in a society where myths, misbeliefs, and misconceptions are quite common. Psychological insulin resistance is also a real phenomenon. Many diabetics often feel that insulin is the last option, and once initiated, it can never be stopped, and its initiation is the beginning of the end. They fear taking the injection and feel that there is a stigma associated with insulin. Insulin therapy can, in fact, be a real painful therapy. As a consequence, compliance to an insulin regimen has been difficult for many patients. ${ }^{50,51}$

Health care providers, on the other hand, also experience psychological resistance to insulin therapy. They may also fear hypoglycemia and have concern for their patients' safety. ${ }^{52}$

The majority of T2DM diabetics are obese, and the risk of increasing weight further adds to the complexity of the decision to initiate insulin. All these, combined with the time it takes to educate the patient and titrate the dose, add up to a lot of work. Therefore, a diabetes educator can play a key role in mitigating many false beliefs and improving adherence and compliance to insulin regimen. ${ }^{53}$ Every patient must be educated about the actions of insulin, the impact of food and physical activity on blood glucose, the importance of self-monitoring of blood glucose, and the importance of overall blood glucose control. To overcome the psychological insulin resistance experienced by the patient, it is important to begin the conversation early. Patient must be told that diabetes is a progressive disease and that eventually most people with T2DM will require insulin to achieve normal blood glucose.

\section{Indications for insulin initiation}

Exposure to chronic hyperglycemia results in glucotoxicity, lipotoxicity to pancreatic beta cells, oxidative stress, and overproduction of reactive oxygen species, which affect the insulin promoter genes expression and augment beta-cell dysfunctions. ${ }^{54}$ Despite all the odds and barriers to insulin therapy, certain population would clearly benefit from early insulinization. ${ }^{55}$ Glucotoxicity can be reversed after institution of insulin and achieving normoglycemia, and beta cells recover to a much greater extent in those exposed to shorter duration of hyperglycemia. ${ }^{56,57}$

Therefore, for patients presenting with severe hyperglycemia, insulin should be administered as soon as possible to quickly achieve normoglycemia. Following are the indications to initiate insulin therapy in T2DM.
- Hyperglycemic hyperosmolar state

- Diabetic ketoacidosis

- Critically ill patient

- Moderate-to-severe vital organ dysfunctions

- Perioperative period before major surgery

- Failure to oral antihyperglycemic treatment

- Fasting plasma glucose (FPG) levels $>250 \mathrm{mg} / \mathrm{dL}$

- Random plasma glucose $>300 \mathrm{mg} / \mathrm{dL}$

- Initial glycosylated $\mathrm{HbA}_{1 \mathrm{c}}>9 \%$

- Pregnancy and lactation.

\section{Potential advantages of early insulinization}

Insulin therapy should not be considered as the last treatment option. Rather, the initiation of insulin should be considered early in the course of disease. Early insulinization may help patients achieve long-term glycemic control and improved quality of life, and results in rapid reversibility of glucolipotoxicity, reduction of the inflammatory markers and cardiovascular risk, and preservation of beta-cell mass and functions. One study showed that $>95 \%$ of patients achieve normoglycemia while receiving insulin as compared with $84 \%$ receiving oral agents. ${ }^{58}$ Patients on insulin therapy achieve much quicker normoglycemia and increment in Homeostasis Model Assessment of beta-cell function compared to oral therapy. ${ }^{59}$

\section{Conventional human insulin vs analog insulin}

Insulin is secreted round the clock by beta cells of pancreas. Its release is augmented by carbohydrate meal and characterized by quick first-phase release followed by slower second-phase release. ${ }^{60}$ Conventional human insulin may not mimic the similar pharmacokinetics, and analog insulins were introduced so as to physiologically simulate the normal insulin pharmacokinetic profile. Regular human insulin slowly absorbs from the subcutaneous tissues, takes at least 30 minutes to exert effect, and peaks after 2 hours (Table 3 ). Both postprandial hyper- and hypoglycemia are commonly observed with regular insulin. The conventional basal Neutral Protamine Hagedorn (NPH) insulin has variable rates of absorption from subcutaneous tissues and duration of action less than 24 hours resulting in fasting hyperglycemia and nocturnal hypoglycemia. ${ }^{61,62}$

U-500 regular insulin has a pharmacokinetic profile similar to NPH and is specially indicated in severely insulinresistant patients. One study showed that patients who require insulin doses more than 200 IU were switched to U-500 insulin twice a day and achieved better glycemic control. ${ }^{63}$ 
Analog insulins are relatively new insulin formulations and produced by changing amino acid sequence from the human insulin. Modification in amino acid sequences causes a change in physiological properties of analog insulins. The three rapid-acting analogs (aspart, glulisine, lispro) dissociate and absorb quickly after subcutaneous injection and take effect as early as 5 minutes and achieve peaks very early as compared to regular insulin.

Insulin glargine, the first long-acting insulin analog, has no significant peak and works nearly for 24 hours and is given once a day only ${ }^{64,65}$ Detemir, another long-acting basal analog, has duration of action of 20 hours and can be given once or twice daily. Both long-acting basal analogs have a nonsignificant or limited peak and longer duration of action and fewer incidences of side effects than conventional NPH insulin. ${ }^{66,67}$

In one meta-analysis, glycemic control was not improved with analog insulin compared to human insulin, but nocturnal hypoglycemia was reduced. ${ }^{68,69}$ Conventional human insulin and analogs are supposed to have similar efficacy toward lowering glycosylated $\mathrm{HbA}_{1 \mathrm{c}}$. However, cost, safety, efficacy, and individual preferences should be considered while prescribing any type of insulin.

\section{Initiating insulin therapy}

Insulin therapy should always begin with diet control, weight reduction, and exercise. A well-educated and motivated individual may get normoglycemia soon if strictly adhered to lifestyle changes. In T2DM, there is a relative insulin deficiency, and endogenous insulin may be sufficient to control postprandial glucose excursion, and often, basal insulin supplement once a day is enough to control hyperglycemia. If not adequately controlled, then premeal bolus insulin or premixed preparations can also be used. Insulin may be used alone or in combination with other oral medications, such as metformin, GLP-1 analog, thiazolidinediones, and DPP-4 inhibitors. Health care provider must be careful while prescribing insulin with thiazolidinedione because of much weight gain and risk of worsening heart failure. However, combination of insulin with metformin results in much better glycemic control, low incidence of hypoglycemia, and minimum weight gain. ${ }^{70}$

The term "insulin intensification" has been used to describe multiple insulin doses and incorporate basal insulin delivery with prandial doses of short- or rapid-acting insulin analogs three or more times daily. Although this intensive regimen is best suited for $\mathrm{T} 1$ diabetes, it can also be used for uncontrolled T2DM patients.
Basic recommendations to initiate insulin therapy

If FPG is elevated, insulin therapy can be initiated with longacting or intermediate-acting basal insulin.

If postprandial glucose is elevated, rapid-acting analog or regular insulin (bolus insulin) can be used.

If both FPG and postprandial plasma glucose are elevated, any of the following combinations would be appropriate.

- Oral agents with basal insulin

- Premixed insulin analogs or premixed conventional human insulin

- Basal/bolus as in multiple daily injections or an insulin pump.

\section{Basal insulin}

As described in the "Conventional human insulin vs analog insulin" section, basal insulin analogs provide insulin concentration for 24 hours and result in much less incidence of hypoglycemic events. Therefore, basal analogs are preferred over NPH insulin, although both kinds of basal preparations are equally effective in reducing glycosylated $\mathrm{HbAlc} .^{71,72}$

For patients who remain uncontrolled despite receiving more than two oral antihyperglycemic drugs, basal insulin may be added as an add-on therapy to current regimen. Starting dose of basal insulin depends on the level of glycemic control at the time of presentation. If $\mathrm{HbA}_{1 \mathrm{c}}$ is $\leq 8.0 \%$, then basal insulin can be used at the rate of $0.1-0.2 \mathrm{U} / \mathrm{kg}$, and higher doses $(0.2-0.4 \mathrm{U} / \mathrm{kg})$ are indicated for those patients with very poor glycemic control and $\mathrm{HbA}_{1 \mathrm{c}}$ more than $8 \%$. This starting dose should be adjusted regularly according to patients' needs to achieve tighter and better glycemic control, while avoiding hypoglycemia as much as possible. ${ }^{73}$

Patients with severe insulin resistance may require much higher dose $((\geq 1 \mathrm{U} / \mathrm{kg})$ to overcome insulin resistance and achieve glycemic control.

If plasma glucose level falls below $70 \mathrm{mg} / \mathrm{dL}$, insulin dose should be reduced by $10 \%-20 \%$, and in case of severe hypoglycemia, dose may be further reduced by $20 \%-40 \%$.

\section{Bolus insulin}

Regular insulin is short-acting bolus insulin, the effect of which appears 30 minutes after subcutaneous injection and lasts 4-6 hours requiring frequent administration to control prandial plasma glucose. Continuous intravenous infusions of regular insulin are particularly useful in the acute medical emergency such as diabetic ketoacidosis and hyperglycemic hyperosmolar states and during the perioperative management of insulinrequiring diabetics undergoing major surgical interventions.

Rapid-acting analogs have quicker onset of action, peak quite early, and have shorter duration of action because 
of rapid degradation to insulin monomers as compared to conventional human regular insulin (Table 3). Rapid-acting analogs or short-acting insulin should be added to basal insulin when postprandial glucose remains elevated or when fasting glucose is under control, but $\mathrm{HbA}_{1 \mathrm{c}}$ remains elevated. Dose of bolus insulin should be given as $10 \%$ of the total basal insulin before each meal as suggested in the Treating To Target in Type 2 Diabetes (4-T) study. ${ }^{74}$ The results of the 4-T study support the initial addition of basal insulin to oral antihyperglycemic agents among uncontrolled patients with T2DM and the addition of rapid-acting prandial insulin in those still not achieving desired control.

\section{Premixed insulin}

Regular insulin mixed with NPH as well as rapid-acting insulin analogs mixed with their intermediate-acting protamine suspension provides prandial and fasting glucose coverage and avoids multiple injections and improves compliance. Premixed insulin dosage is difficult to titrate in the event of fluctuating plasma glucose because of having fixed combination.

Basal-bolus insulin regimens

Patients who suffer from symptomatic hyperglycemia and remain uncontrolled as reflected by $\mathrm{HbA}_{1 \mathrm{c}}$ more than $8 \%$ despite receiving basal insulin or premixed insulin may respond to combination of basal plus bolus regimen. An extensive regimen of once or twice basal coverage with shortacting regular or rapid-acting analogs at each meal proves the most effective strategy to get euglycemic states and provides much flexibility for those patients who have variable meal times and carbohydrate contents. ${ }^{75}$

If patients remain uncontrolled despite intensified basalbolus regimen, then subcutaneous insulin infusion pump should be considered.

\section{Combination of basal insulin with GLP-I analog}

Researchers found in a review and meta-analysis that the combination of GLP-1 agonists and basal insulin beats other T2DM treatments at lowering $\mathrm{HbA}_{1 \mathrm{c}}$ and improving glycemic control.

In a pooled analysis of 15 studies, there was a significantly greater mean reduction in $\mathrm{HbA}_{1 \mathrm{c}}(-0.44 \%)$ against all other comparators. This meta-analysis comprising 4,348 patients found that the combination of GLP-1 and basal insulin offered a significantly greater reduction in $\mathrm{HbA}_{1 \mathrm{c}}$ than any other treatment strategy $(P<0.0001)$ and lend support to the use of GLP-1 agonists in combination with basal insulin in the clinical management of patients with T2DM. Patients taking the combination also had significantly greater weight loss, and there was no increased risk of hypoglycemia. However, cost may be a limiting factor for this combination therapy. ${ }^{76,77}$

\section{Summary of recommendations to insulinization}

One injection:

- Intermediate-acting insulin or long-acting analog at bedtime

- Premixed conventional or analog before dinner.

Two injections:

- Twice daily breakfast and dinner premixed formulation

- Breakfast and dinner: combination of short-acting or rapid-acting plus NPH or long-acting insulin analog.

\section{Three injections:}

- Add on short- or rapid-acting insulin at lunchtime to a twice daily premixed regimen

- Add on a third premix injection at lunchtime to a twice daily premixed regimen

- Intermediate- or long-acting insulin analog at bedtime with short-acting or rapid-acting insulin analog at breakfast and dinner.

\section{Multiple injections:}

- Short-acting or rapid-acting insulin analog at each meal with an intermediate human insulin or long-acting analog at bedtime.

\section{Combination of basal insulin with GLP-I analog:}

- Exenatide or liraglutide can be added to existing basal analog regimen.

\section{Insulin pump:}

- Alternative to multiple daily injections.

\section{Side effects of insulin therapy}

\section{Hypoglycemia}

Hypoglycemia is a common and serious complication of insulin therapy, and fortunately, fatality from such occurrence is rarely encountered and considered a major obstacle to achieving target glucose control.

Patients with longer duration of diabetes are especially at risk because of progressive loss of beta-cell mass and more dependence on exogenous insulin with increasing dose requirement with the passage of time. Following are the other risk factors and associated medical conditions causing hypoglycemia in insulin-treated patients. 
- Vigorous exercise

- Missed meals

- Overdosage

- Renal insufficiency

- Older age

- Liver diseases

- Hypothyroidism

- Hypocortisolism

- Hypopituitarism.

Achieving stringent glycemic control by intensive insulin therapy is also one of the contributing factors causing hypoglycemic events. This notion is supported by many landmark trials such as the Veterans Affairs Diabetes Trial (VADT), ADVANCE, and Action to Control Cardiovascular Risk in Diabetes (ACCORD). In the VADT and ADVANCE studies, intensive therapy leading to a mean $\mathrm{HbA}_{1 \mathrm{c}}$ of $6.3 \%-6.9 \%$ (vs $7.0 \%-8.5 \%$ in the standard control group) resulted in severe hypoglycemia among $2.7 \%-21.2 \%$ of subjects, compared with $1.5 \%-9.9 \%$ in the standard therapy group. ${ }^{46,78}$ This scenario further complicated in the ACCORD trial where severe hypoglycemia resulted in greater mortality rate. ${ }^{79}$

Incidence of hypoglycemia can be minimized by appropriate selection of insulin, dosage, timing of administration, and compliance to diet and exercise. Occurrence of hypoglycemia first time predicts future occurrence as well, and almost one third may experience second episode within 4 months.

\section{Weight gain}

Weight gain is also a common problem encountered in insulin-treated patients, and degree of weight gain varies from one insulin type to another and is seen more commonly with conventional insulin than analogs. Among the basal insulin analogs, insulin detemir results in less weight gain than insulin glargine, although glycemic control was comparable. $^{80,81}$

\section{Risk of malignancy}

T2DM is associated with numerous soft and solid tissue tumors such as cancer of the breast, pancreas, colorectal, liver, kidney, and endometrium and non-Hodgkin lymphoma. It has been observed that patients with malignant condition and T2DM using insulin carry greater mortality. Insulin glargine has been shown to demonstrate increased mitogenic potency and higher binding affinity to insulin-like growth factors (IGF-1). However, glargine is rapidly degraded to metabolites, and these metabolites show very little binding affinity to IGF-1. A recent review on glargine did not support an increased risk of malignancy among glargine-treated patients when compared to other insulin therapies. ${ }^{82}$

\section{Newer insulin formulations}

New technologies are merging in the development of newer insulin formulations to provide more physiological profile and better glycemic control and minimize side effects.

Insulin degludec

Insulin degludec is an ultra-long-acting basal analog in multihexamer form and has a half-life of more than 24 hours. After subcutaneous injection, hexamers transform slowly into monomers, and these monomers gradually absorb into blood stream. In one study, degludec was compared to glargine, and after 16 weeks of trial, it was concluded that degludec once daily or three times per week caused more reduction in $\mathrm{HbA}_{1 \mathrm{c}}$ and less hypoglycemia compared to glargine once a day. ${ }^{83}$

\section{Linjeta}

Linjeta (formerly VIAject) is an ultrafast-acting human insulin and contains ethylene diaminetetraacetic acid and citric acid. These chemical substances cause more rapid degradation of hexamers to monomers and more rapid peak followed by faster decrease in insulin level after subcutaneous administration. The time to half maximal activity of Linjeta was found to be 33 minutes, 18 minutes faster than insulin lispro and 33 minutes faster than regular human insulin. ${ }^{84}$ Linjeta has been shown to decrease oxidative stress and postprandial hyperglycemia and hypoglycemia and improve endothelial functions in T2DM. ${ }^{85}$

\section{Biosimilar insulins}

Biosimilar insulin is defined as a copy of an original research biological molecule that is already approved for clinical use such as insulin lispro and glargine. First biosimilar insulin glargine has already been approved by European Union.

The US Food and Drug Administration (FDA) is likely to give approval of biosimilar insulin after expiry of patent protection of analogs such as insulin lispro. ${ }^{86}$ Manufacturers use the similar, but not identical techniques in making biosimilar insulin, which may differ in certain physiological and pharmacological characteristics. ${ }^{87}$ Biosimilar insulin may reduce the cost of insulin, increase the accessibility, and expand the brand available in the market. On the other hand, it must demonstrate efficacy, safety, and tolerability as demonstrated by original molecules manufactured by patent holders. ${ }^{88}$

\section{Inhaled insulin}

Exubera, the first inhaled insulin preparation approved by the FDA, is no longer available. Afrezza, the second inhaled insulin approved by FDA in April 2014, is an ultra-rapidacting form of inhalable insulin. Peak plasma concentrations are attained at 10-15 minutes after inhalation that mimic physiologic mealtime response. Cough is the most common 
side effect, and mild-to-moderate hypoglycemia has also been reported.

\section{GLP-I analog}

GLP-1 is an incretin-based peptide hormone, produced by the L cells of the small intestine and mediates glucosedependent insulin release. After coming into circulation, GLP-1 is rapidly degraded by the enzyme DPP-4. Its half-life is only 1-2 minutes, and it is rapidly cleared by kidneys. The natural peptide hormone, therefore, cannot be used therapeutically, and GLP-1 receptor agonists are manufactured to bypass enzymatic degradation. There are two GLP-1 receptor agonists available for T2DM, exenatide and liraglutide, and administered subcutaneously. Their mechanism is similar to naturally occurring GLP-1, but they bind to GLP-1 receptor and exert their pharmacological effects. ${ }^{89}$

GLP-1 receptor agonists are found to be effective in reducing both fasting and postprandial glucose excursions. Their effects are more robust if combined with oral agents or basal insulin..$^{90}$

Following is the brief description of currently available GLP-1 analogs.

\section{Exenatide}

Exenatide appears to lower $\mathrm{HbA}_{1 \mathrm{c}}$ levels by $0.5 \%-1 \%$, by lowering fasting and postprandial blood glucose levels..$^{91,92}$ Exenatide exerts its effects by glucose-dependent insulin release, suppressing appetite, slowing gastric emptying, and reducing glucagon secretion. When used as monotherapy, it is not associated with hypoglycemia, though gastrointestinal disturbance is commonly encountered, and $30 \%-45 \%$ of exenatide-treated patients suffer from nausea, vomiting, and diarrhea. One advantage of using exenatide is that it causes weight reduction and indicated especially for obese T2DM who remained uncontrolled on oral medications.

Exenatide is dispensed as two fixed-dose pens $(5 \mu \mathrm{g}$ and $10 \mu \mathrm{g}$ ). It is injected subcutaneously 60 minutes before meal. Patients should be initiated with $5 \mu \mathrm{g}$ pen for the first month, and the dose can then be increased to $10 \mu \mathrm{g}$ twice a day if patients tolerate well. It is excreted primarily by kidneys; therefore, it is contraindicated in renal failure patients.

In the Diabetes Therapy Utilization: Researching Changes in $A_{1 c}$, Weight and Other Factors Through Intervention With Exenatide Once Weekly (DURATION-5) study, exenatide once-weekly formulation was compared to exenatide twice-daily preparations. It was concluded that once-weekly formulation provided much better glycemic control and tolerability than did twice-daily administration. ${ }^{93}$ Dose of the long-acting exenatide (Bydureon) is $2 \mathrm{mg}$ once a week.

The FDA recently approved another once-weekly formulation, albiglutide (Tanzeum). Dose is $30 \mathrm{mg}$ subcutaneously once weekly, and may increase to $50 \mathrm{mg}$ once weekly if glycemic response is inadequate.

\section{Liraglutide}

Its mechanism of action is similar to exenatide, but it has long plasma half-life of 8-14 hours; therefore, it is administered once a day only. Its starting dose is $0.6 \mathrm{mg}$ and can be gradually titrated up to $1.8 \mathrm{mg}$ depending upon the tolerance and glycemic control.

\section{Side effects of GLP-I receptor agonists}

Gastrointestinal disturbances are frequently encountered, and one third of patients may suffer from nausea and vomiting. Diarrhea is also reported in 10\% of GLP-1 users. Few cases of acute pancreatitis have also been reported in patients taking liraglutide. One animal study showed that liraglutide stimulated C-cell hyperplasia and caused medullary thyroid carcinoma in rats. Fortunately, human C-cells express very few GLP-1 receptors, and it is still unclear whether GLP-1 agonist is associated with similar outcome observed in animal study. ${ }^{94}$ Therefore, GLP-1 analog is contraindicated in patients with personal or family history of medullary thyroid carcinoma or multiple endocrine neoplasia syndrome type 2 .

\section{Amylin analog}

Amylin is a 37-amino acid peptide that is stored in pancreatic beta cells and is co-secreted with insulin. Amylin and insulin levels rise and fall in a synchronous manner. Amylin and insulin have complementary actions in regulating nutrient levels in the circulation. Amylin is found to be deficient in both $\mathrm{T} 1$ and T2DM.

\section{Pramlintide}

Pramlintide (Symlin) is an amylin analog that mimics the effects of endogenous amylin, which is secreted by pancreatic beta cells. Mechanism of action of pramlintide is similar to GLP-1 analog, and it is administered subcutaneously before meals. In clinical studies, $\mathrm{HbA}_{1 \mathrm{c}}$ has been decreased by $0.5-0.7$ percentage points. ${ }^{95}$

The major clinical side effects of this drug are gastrointestinal in nature. Use of the amylin analog pramlintide in conjunction with bolus insulin improves glycemia and reduces weight in patients with T2DM. ${ }^{96}$ 
Pramlintide is approved for use in patients with $\mathrm{T} 1$ and T2DM taking insulin. It is recommended to reduce postprandial short-acting insulin dose by $50 \%$ before initiating pramlintide. The recommended starting dose for $\mathrm{T} 1$ diabetes is $15 \mu \mathrm{g}$ before each meal, with increases of $15 \mu \mathrm{g}$ every 3-7 days, as tolerated, to a goal of $60 \mu \mathrm{g}$ before each meal. Persistent nausea should prompt backward titration until resolved. The recommended initial dose for T2DM is $60 \mu \mathrm{g}$, titrated upward as tolerated to $120 \mu \mathrm{g}$ with each meal.

\section{Role of bariatric surgery in T2DM treatment}

Bariatric surgery is recommended for a selective group of diabetes patients with obesity. However, weight-loss surgery is the most effective treatment for morbid obesity, producing durable weight loss, improvement, or remission of comorbid conditions like T2DM, and longer life. ${ }^{97}$

According to the 1991 National Institutes of Health consensus conference on gastrointestinal surgery for severe obesity, following patients are candidates for bariatric procedures.

- Morbidly obese (body mass index $>40 \mathrm{~kg} / \mathrm{m}^{2}$ )

- Body mass index $\geq 35 \mathrm{~kg} / \mathrm{m}^{2}$ with comorbidities

- Failure to lifestyle modifications.

To qualify for surgery, patients must be well informed, motivated, and free of significant vital organ dysfunctions and psychological disease. In addition, the expected benefits of operation must outweigh the risks.

Two mechanisms have been proposed to explain this rapid normalization of glucose control after gastric bypass. The first suggests reduction of insulin resistance, a hallmark feature of T2DM. The second involves exaggerated responses from the distal small bowel to nutrients. In the latter hypothesis, gut hormones produced in the distal small bowel such as GLP-1 may act as incretins stimulating the beta cells in the pancreas to restore normal first-phase insulin responses. ${ }^{98}$

However, a long-term follow-up study showed that after 15 years, the diabetes remission rates decreased to $6.5 \%$ for control patients and to $30.4 \%$ for bariatric surgery patients $(P<0.001) .{ }^{99}$ This might explain the progressive beta-cell failure in long-standing diabetes and resulting in initiation of hormonal therapy.

\section{Future directions to hormonal treatment}

There is a pressing need for a new and effective therapeutic strategy for addressing the epidemic of T2DM, and following is a short description of the future potential hormonal therapy for DM.

\section{Betatrophins}

Betatrophin has recently been described as a key hormone to stimulate beta-cell mass expansion in response to insulin resistance and obesity in mice. ${ }^{100,101}$

The finding has generated an interest in the development of antidiabetes drugs with betatrophin as the active component.

Liver and fat cell primarily express betatrophin. Animal studies have suggested that beta-cell proliferations occurred in response to expression of betatrophins during gestation and insulin resistance in mouse models. In this model, expression of betatrophin led to expansion of beta-cell mass and proliferation and improved glucose tolerance. Therefore, it is presumed that betatrophin therapy might result in cure of diabetes in future.

\section{Leptin}

Leptin is a hormone produced by fat cells, which regulates the amount of fat stored in the body. It does this by adjusting both the sensation of hunger and energy expenditures. Hunger is inhibited when the amount of fat stored reaches a certain level. Leptin is then secreted and circulates through the body, eventually activating leptin receptors in the arcuate nucleus of the hypothalamus. Energy expenditure is increased both by the signal to the brain and directly via leptin receptors on peripheral targets. ${ }^{102}$

Leptin was first introduced in 1994, and since then, numerous animal studies have been conducted to further explore cellular and biological impact in the body. Leptin gene therapy in animal models not only improved glucose tolerance in both T1 and T2DM but also decreased obesity. Apart from these beneficial effects, leptin was also found to improve triglycerides in lipodystrophy associated with severe insulin resistance. Although results from these studies are quite optimistic, more studies are needed to determine the safety, efficacy, and clinical indications to treat obesity and diabetes..$^{103,104}$

\section{Ghrelin}

Ghrelin is a peptide hormone produced by neuroendocrine ghrelin cells of gastrointestinal tract and plays a significant role in regulating hunger and energy balance. Ghrelin is secreted when stomach is empty, and its production stops when stomach is stretched or full of food contents. This neuroendocrine hormone exerts physiological effects by acting on receptors present on hypothalamus. It increases hunger, gastric acid secretion, and gastrointestinal motility, effects opposite to leptin.

Pharmaceutical companies have started actively to develop drugs that can target orexigenic or obesity-related 
functions of ghrelin and its receptor. Ghrelin receptor antagonists are shown to block growth hormone secretion and thus improve the diabetic condition by promoting glucose-dependent insulin secretion and weight loss and suppressing appetite. ${ }^{105,106}$ Other potential therapeutic molecules under consideration include glucagon receptor antagonists, pancreatic-G-protein-coupled fatty-acid-receptor agonists, and glucokinase activators.

\section{Dual-hormone artificial pancreas}

Dual-hormone artificial pancreas delivers both insulin and glucagon that are released subcutaneously in response to plasma glucose level sensed by a continuous glucose monitor. A 5-day outpatient trial presented at the American Diabetes Association meeting in June 2014 showed significant declines in plasma glucose levels without hypoglycemic events.

This hormonal device was also tested in another 2-day hospital-based setting of T1DM and showed excellent blood sugar control with minimal hypoglycemia despite highcarbohydrate meals and exercise and strongly justify further evaluation under real-life situation. ${ }^{107}$ We hope this device to be marketed by 2017 . However, this device is currently recommended for T1DM only.

\section{Turning stem cells into beta cells}

Replacement of beta cells is one of the strategies to treat diabetes, and human pancreas has been transplanted successfully to treat people with $\mathrm{T} 1$ diabetes but limited by the availability of donor cells and the side effects of immunosuppression.

Transforming beta cells from stem cell is another approach to treat diabetes. Stem cells have the potential to transform into many different cell types and have been genetically reprogrammed to take on the characteristics of embryonic stem cells. They can grow indefinitely in the laboratory and can theoretically change, or differentiate, into any cell type found in the body.

A team led by Dr Douglas Melton at Harvard University grew a human embryonic stem cell line and two humaninduced pluripotent stem cell lines in a culture system that enabled them to transform human pluripotent stem cells into beta cells that functioned similarly to normal adult beta cells. ${ }^{108}$ Indeed, this experiment is a step forward toward curing diabetes.

\section{Conclusion}

Insulin resistance and beta-cell dysfunctions are the hallmarks of the pathophysiology of T2DM. Incretin hormones also play some roles in glucose homeostasis, and incretin-based therapy is relatively a new approach in the management of T2DM.

Prevention of acute and long-term diabetes complications is the main objective of diabetes treatment. Accelerated deterioration in beta-cell mass was particularly observed in those with poor glycemic control, and patients often get benefit from insulin therapy because of early onset of action, more effective in reducing $\mathrm{HbA}_{1 \mathrm{c}}$ and quickly averting the oxidative stress and glucolipotoxicity to pancreatic beta cells. Landmark clinical trials have shown a clear benefit of insulinization in reducing microvascular and macrovascular complications. After availability of newer therapeutic modalities and newer insulin analogs, treating physicians may find it difficult to select the best treatment modality. New guidelines on diabetes may also help in deciding the appropriate treatment regimen and add-on therapy, which is frequently required when glycemic control is suboptimum. However, selection of a particular regimen should be based on individual need, preference, cost, safety, and efficacy. Uses of nonhormonal antidiabetes drugs do carry more risks, side effects, and limitations to prescribe in certain medical conditions as compared to hormonal therapy such as insulin and incretin-based hormonal therapy. Furthermore, oral antidiabetes treatment requires careful dose titration and has delayed onset of action. GLP-1 and amylin analogs are novel hormonal approaches and should be considered in uncontrolled and obese T2DM.

Diabetes education, lifestyle changes, and dietary modification should remain the part and parcel of diabetes management, and their roles in achieving normoglycemia cannot be overemphasized.

Cure from diabetes remains a dream, and indeed, there is a dire need to develop curative therapeutic modality to effectively combat the epidemic of diabetes, obesity, and metabolic syndrome. There are many potential hormonal therapies under way, and new technologies are emerging toward curing diabetes, and we hope for much better therapeutic options for diabetes treatment in the years to come.

\section{Disclosure}

The author reports no conflicts of interest in this work.

\section{References}

1. American Diabetes Association. Standards of medical care in diabetes. Diabetes Care. 2013;36(Suppl 1):S11-S66.

2. International Diabetes Federation. 2011. Available from: http://www. idf.org/media-events/press-releases/2011/diabetes-atlas-5th-edition.

3. Engelgau MM, Geiss LS, Saaddine JB. The evolving diabetes burden in the United States. Ann Intern Med. 2004;140:945. 
4. Imam K. Management and treatment of diabetes mellitus. Adv Exp Med Biol. 2012;771:356-380.

5. Ali MK, McKeever Bullard K, Saaddine JB, Cowie CC, Imperatore G, Gregg EW. Achievement of goals in US diabetes care, 1999-2010. N Engl J Med. 2013;368(17):1613-1624.

6. Nathan DM, Cleary PA, Backlund JY, et al; Diabetes Control and Complications Trial/Epidemiology of Diabetes Interventions and Complications (DCCT/EDIC) Study Research Group. Intensive diabetes treatment and cardiovascular disease in patients with type 1 diabetes. The diabetes control and complications trial/epidemiology of diabetes interventions and complications (DCCT/EDIC) study research group. N Engl J Med. 2005;353:2643-2653.

7. White NH, Sun W, Cleary PA, et al. Prolonged effect of intensive therapy on the risk of retinopathy complications in patients with type 1 diabetes mellitus: 10 years after the diabetes control and complications trial. Arch Ophthalmol. 2008;126:1707-1715.

8. Unger RH, Orci L. Paracrinology of islets and the paracrinopathy of diabetes. Proc Natl Acad Sci U S A. 2010;107(37):16009-16012.

9. CDC. National Diabetes Fact Sheet: National Estimates and General Information on Diabetes and Prediabetes in the United States; 2011. Available from: http://www.cdc.gov/diabetes/pubs/pdf/ndfs_2011. pdf.

10. Bodmer M, Meier C, Krahenbuhl S, Jick SS, Meier CR. Metformin, sulfonylureas, or other antidiabetes drugs and the risk of lactic acidosis or hypoglycemia: a nested case control analysis. Diabetes Care. 2008;31:2086-2091.

11. Zimmerman BR. Sulfonylureas. Endocrinol Metab Clin North Am. 1997;26:511-521.

12. Saloranta C, Hershon K, Ball M, Dickinson S, Holmes D. Efficacy and safety of nateglinide in type 2 diabetic patients with modest fasting hyperglycemia. J Clin Endocrinol Metab. 2002;87:4171-4176.

13. Yki-Järvinen H. Thiazolidinediones. N Engl J Med. 2004;351:1106.

14. Grey A. Skeletal consequences of thiazolidinedione therapy. Osteoporos Int. 2008;19:129.

15. Schwartz AV, Sellmeyer DE, Vittinghoff E, et al. Thiazolidinedione use and bone loss in older diabetic adults. J Clin Endocrinol Metab. 2006;91:3349.

16. Lebowitz HE. Alpha-glucosidase inhibitors as agents in the treatment of diabetes. Diabetes Rev. 1998;6:132-145.

17. Pospisilik JA, Stafford SG, Demuth HU. Long-term treatment with dipeptidyl peptidase IV inhibitor improves hepatic and peripheral insulin sensitivity in the VDH Zucker rat: a euglycemic-hyperinsulinemic clamp study. Diabetes. 2003;51:2677-2683.

18. Noel RA, Braun DK, Patterson RE, Bloomgren GL. Increased risk of acute pancreatitis and biliary disease observed in patients with type 2 diabetes: a retrospective cohort study. Diabetes Care. 2009;32: 834-838.

19. Raz I, Hanefeld M, Xu L, Caria C, Davies M, Williams-Herman D. Efficacy and safety of the dipeptidyl peptidase-4 inhibitor sitagliptin as monotherapy in patients with type 2 diabetes mellitus. Diabetologia. 2006;49:2564-2571.

20. Edward C, Chao DO. SGLT-2 inhibitors: a new mechanism for glycemic control. Clin Diabetes. 2014;32:4-11.

21. Nair S, Joseph F, Ewins D, Wilding J, Goenka N. From history to reality: sodium glucose co-transporter 2 inhibitors - a novel therapy for type 2 diabetes mellitus. Pract Diabetes Int. 2010;27:311-316.

22. List JF, Woo V, Morales E, Tang W, Fiedorek FT. Sodium-glucose cotransport inhibition with dapagliflozin in type 2 diabetes. Diabetes Care. 2009;32:650-657.

23. Bailey CJ, Turner RC. Metformin. N Engl J Med. 1996;334:574-579.

24. Kahn SE, Haffner SM, Heise MA, et al; ADOPT Study Group. Glycemic durability of rosiglitazone, metformin, or glyburide monotherapy. N Engl J Med. 2006;355:2427-2443.

25. Roumie CL, Hung AM, Greevy RA. Comparative effectiveness of sulfonylurea and metformin monotherapy on cardiovascular events in type 2 diabetes mellitus: a cohort study. Ann Intern Med. 2012;157: 601-610.
26. Zeller M, Danchin N, Simon D, Vahanian A, Lorgis L, Cottin Y. Impact of type of preadmission sulfonylureas on mortality and cardiovascular outcomes in diabetic patients with acute myocardial infarction. J Clin Endocrinol Metab. 2010;95(11):4993-5002.

27. UK Prospective Diabetes Study (UKPDS) Group. Intensive blood glucose control with sulphonylureas or insulin compared with conventional treatment and risk of complication in patients with type 2 diabetes (UKPDS 33). Lancet. 1998;352:837-853.

28. The ADVANCE Collaborative Group. Intensive blood glucose control and vascular outcomes in patients with type 2 diabetes. $N$ Engl J Med. 2008;358:2560-2572.

29. Turner RC. The UK prospective diabetes study: a review. Diabetes Care. 1998;21(Suppl 3):C35-C38.

30. Monami M, Genovese S, Mannucci E. Cardiovascular safety of sulfonylureas: a meta-analysis of randomized clinical trials. Diabetes Obes Metab. 2013;15(10):938-953.

31. Nissen SE, Wolski K. Rosiglitazone revisited: an updated metaanalysis of risk for myocardial infarction and cardiovascular mortality. Arch Intern Med. 2010;170:1191-1201.

32. Dormandy JA, Charbonnel B, Eckland DJA. Secondary prevention of macrovascular events in patients with type 2 diabetes in the PROactive (PROspective pioglitAzone clinical trial in macrovascular events): a randomized controlled trial. Lancet. 2005;366:1279-1289.

33. Chiasson JL, Josse RG, Gomis R, Hanefeld M, Karasik A, Laakso M. Acarbose treatment and the risk of cardiovascular disease and hypertension in patients with impaired glucose tolerance: the STOPNIDDM Trial. JAMA. 2003;290:486-494.

34. Scheen AJ. Cardiovascular effects of dipeptidyl peptidase-4 inhibitors: from risk factors to clinical outcomes. Postgrad Med. 2013;125(3): $7-20$.

35. Dziuba J, Alperin P, Racketa J, et al. Modeling effects of SGLT-2 inhibitor dapagliflozin treatment versus standard diabetes therapy on cardiovascular and microvascular outcomes. Diabetes Obes Metab. 2014;16(7):628-635.

36. Fisman EZ, Tenenbaum A, Motro M, Adler Y. Oral antidiabetic therapy in patients with heart disease. A cardiologic standpoint. Herz. 2004;29(3):290-298.

37. Leahy JL, Hirsch IB, Peterson KA, Schneider D. Targeting $\beta$-cell function early in the course of therapy for type 2 diabetes mellitus. J Clin Endocrinol Metab. 2010;95:4206-4216.

38. UK prospective diabetes study 16 . Overview of 6 years' therapy of type II diabetes: a progressive disease. Diabetes. 1995;44(11):1249-1258.

39. Gastaldelli A, Ferrannini E, Miyazaki Y, Matsuda M, DeFronzo RA. Beta-cell dysfunction and glucose intolerance: results from the San Antonio metabolism (SAM) study. Diabetologia. 2004;47(1):31-39.

40. Centers for Disease Control and Prevention 2011. National Diabetes Fact Sheet; 2011. Available from: http://www.cdc.gov/diabetes/pubs/ pdf/ndfs_2011.pdf.

41. Ohkubo Y, Kishikawa H, Araki E, et al. Intensive insulin therapy prevents the progression of diabetic microvascular complications in Japanese patients with non-insulin-dependent diabetes mellitus: a randomized prospective 6-year study. Diabetes Res Clin Pract. 1995;28: $103-117$.

42. Holman RR, Paul SK, Bethel MA, Matthews DR, Neil HA. 10-year follow-up of intensive glucose control in type 2 diabetes. $N$ Engl J Med. 2008;359:1577-1589.

43. AACE Comprehensive Diabetes. Management algorithm. Endocr Pract. 2013;19:327-336.

44. Nathan DM, Buse JB, Davidson MB, et al. Management of hyperglycemia in type 2 diabetes: a consensus algorithm for the initiation and adjustment of therapy. Diabetes Care. 2006;29:1963-1972.

45. Shichiri M, Kishikawa H, Ohkubo Y, Wake N. Long-term results of the Kumamoto study on optimal diabetes control in type 2 diabetic patients. Diabetes Care. 2000;23(Suppl 2):B21-B29.

46. Duckworth W, Abraira C, Moritz T, et al; VADT Investigators. Glucose control and vascular complications in veterans with type 2 diabetes. N Engl J Med. 2009;360:129-139. 
47. Patel A, MacMahon S, Chalmers J, et al; ADVANCE Collaborative Group. Intensive blood glucose control and vascular outcomes in patients with type 2 diabetes. N Engl J Med. 2008;358:2560-2572.

48. Meneghini LF. Early insulin treatment in type 2 diabetes. Diabetes Care. 2009;32:S266-S269.

49. Hirsch IB, Bergenstal RM, Parkin CG, Wright E, Buse JB. A real-world approach to insulin therapy in primary care practice. Clin Diabetes. 2005;23:78-86.

50. Korytkowski M. When oral agents fail: practical barriers to starting insulin. Int J Obes Relat Metab Disord. 2002;26:518-524.

51. Marre M. Before oral agents fail: the case for starting insulin early. Int J Obes Relat Metab Disord. 2002;26:S25-S30.

52. Larne AC, Pugh JA. Attitudes of primary care providers toward diabetes. Diabetes Care. 1998;21:1391-1396.

53. Nichols GA, Gandra SR, Chiou CF, Anthony MS, Alexander-Bridges M, Brown JB. Successes and challenges of insulin therapy for type 2 diabetes in a managed-care setting. Curr Med Res Opin. 2010;26(1): 9-15.

54. Unger RH, Grundy S. Hyperglycemia as an inducer as well as a consequence of impaired islet cell function and insulin resistance: implications for the management of diabetes. Diabetologia. 1985;28: 119-121.

55. Poitout V, Robertson RP. Glucolipotoxicity: fuel excess and beta-cell dysfunction. Endocr Rev. 2008;29:351-366.

56. Gleason CE, Gonzalez M, Harmon JS, Robertson RP. Determinants of glucose toxicity and its reversibility in the pancreatic islet betacell line, HIT-T15. Am J Physiol Endocrinol Metab. 2000;279: E997-E1002.

57. Garvey WT, Olefsky JM, Griffin J, Hamman RF, Kolterman OG. The effect of insulin treatment on insulin secretion and insulin action in type II diabetes mellitus. Diabetes. 1985;34:222-234.

58. Weng J, Li Y, Xu W, et al. Effect of intensive insulin therapy on betacell function and glycemic control in patients with newly diagnosed type 2 diabetes: a multicentre randomized parallel-group trial. Lancet. 2008;371:1753-1760.

59. Pfützner A, Lorra B, Abdollahnia MR, et al. The switch from sulfonylurea to preprandial short-acting insulin analog substitution has an immediate and comprehensive $\beta$-cell protective effect in patients with type 2 diabetes mellitus. Diabetes Technol Ther. 2006;8:375-384.

60. Ritzel RA, Bulter PC. Physiology of glucose homeostasis and insulin secretion. In: Leahy JL, Cefalu WT, editors. Insulin Therapy. New York, NY: Marcel Dekker; 2002:61-72.

61. Hirsch IB. Insulin analogues. $N$ Engl J Med. 2005;352:174-183.

62. Holleman F, Gale E. Nice insulins, pity about the evidence. Diabetologia. 2007;50:1783-1790.

63. Davidson MB, Navar MD, Echeverry D, Duran P. U-500 regular insulin: clinical experience and pharmacokinetics in obese, severely insulinresistant type 2 diabetic patients. Diabetes Care. 2010;33:281-283.

64. DeVries JH. Pharmacokinetic and glucodynamic variability: assessment of insulin glargine, NPH insulin and insulin ultralente in healthy volunteers using a euglycaemic clamp technique: response to Scholtz HE et al. Diabetologia. 2006;49:1125-1126.

65. Heise T, Pieber TR. Towards peakless, reproducible and long-acting insulins: an assessment of the basal analogues based on isoglycemic clamp studies. Diabetes Obes Metab. 2007;9:648-659.

66. Plank J, Bodenlenz M, Sinner F, et al. A double-blind, randomized, doseresponse study investigating the pharmacodynamic and pharmacokinetic properties of the long-acting insulin analog detemir. Diabetes Care. 2005;28:1107-1112.

67. Porcellati F, Rossetti P, Busciantella NR, et al. Comparison of pharmacokinetics and dynamics of the long-acting insulin analogs glargine and detemir at steady state in type 1 diabetes: a double-blind, randomized, crossover study. Diabetes Care. 2007;30:2447-2452.

68. Ross SA, Zinman B, Campos RV, Strack T; Canadian Lispro Study Group. A comparative study of insulin lispro and human regular insulin in patients with type 2 diabetes mellitus and secondary failure of oral hypoglycemic agents. Clin Invest Med. 2001;24(6):292-298.
69. Horvath K, Jeitler K, Berghold A, et al. Long-acting insulin analogues versus NPH insulin (human isophane insulin) for type 2 diabetes mellitus. Cochrane Database Syst Rev. 2007;18:CD005613.

70. Yki-Järvinen H. Combination therapies with insulin in type 2 diabetes. Diabetes Care. 2001;24:758-767.

71. Monami M, Marchionni N, Mannucci E. Long-acting insulin analogues versus NPH human insulin in type 2 diabetes: a meta-analysis. Diabetes Res Clin Pract. 2008;81:184-189.

72. Home PD, Fritsche A, Schinzel S, Massi-Benedetti M. Meta-analysis of individual patient data to assess the risk of hypoglycemia in people with type 2 diabetes using NPH insulin or insulin glargine. Diabetes Obes Metab. 2010;12:772-779.

73. AACE. AACE comprehensive diabetes management. Endocr Pract. 2013;19(Suppl 1):1-48.

74. Holman RR, Farmer AJ, Davies MJ, et al; 4-T Study Group. Three-year efficacy of complex insulin regimens in type 2 diabetes. $N$ Engl J Med. 2009;361:1736-1747.

75. Leahy JL. Insulin therapy in type 2 diabetes mellitus. Endocrinol Metab Clin North Am. 2012;41:119-144.

76. Eng C, Kramer CK, Zinman B, Retnakaran R. Glucagon-like peptide-1 receptor agonist and basal insulin combination treatment for the management of type 2 diabetes: a systematic review and meta-analysis. Lancet. 2014;384(9961):2228-2234.

77. Young L, Buse JB. GLP-1 receptor agonists and basal insulin in type 2 diabetes. Lancet. 2014;384(9961):2180-2181.

78. Gerstein HC, Miller ME, Byington RP, et al; Action to Control Cardiovascular Risk in Diabetes Study Group. Effects of intensive glucose lowering in type 2 diabetes. N Engl J Med. 2008;358:2545-2559.

79. Bonds DE, Miller ME, Bergenstal RM, et al. The association between symptomatic, severe hypoglycemia and mortality in type 2 diabetes: retrospective epidemiological analysis of the ACCORD study. BMJ. 2010;340:b4909.

80. Rosenstock J, Davies M, Home PD, Larsen J, Koenen C, Schernthaner G. A randomized, 52-week, treat-to-target trial comparing insulin detemir with insulin glargine when administered as add-on to glucose-lowering drugs in insulin-naive people with type 2 diabetes. Diabetologia. 2008;51:408-416.

81. Raskin P, Gylvin T, Weng W, Chaykin L. Comparison of insulin detemir and insulin glargine using a basal-bolus regimen in a randomized, controlled clinical study in patients with type 2 diabetes. Diabetes Metab Res Rev. 2009;25:542-548.

82. Mussig K, Staiger H, Kantartzis K, Fritsche A, Kanz L, Häring HU.Type 2 diabetes mellitus and risk of malignancy: is there a strategy to identify a subphenotype of patients with increased susceptibility to endogenous and exogenous hyperinsulinism? Diabet Med. 2011;28:276-286.

83. Zinman B, Fulcher G, Rao PV, et al. Insulin degludec, an ultra-longacting basal insulin, once a day or three times a week versus insulin glargine once a day in patients with type 2 diabetes. Lancet. 2011;377: 924-931.

84. Steiner S, Hompesch M, Pohl R, et al. A novel insulin formulation with a more rapid onset of action. Diabetologia. 2008;51:1602-1606.

85. Forst T, Pfützner A, Flacke F, et al. Postprandial vascular effects of VIAject compared with insulin lispro and regular human insulin in patients with type 2 diabetes. Diabetes Care. 2010;33:116-120.

86. US Food and Drug Administration. Guidance for Industry: Quality Considerations in Demonstrating Biosimilarity to a Reference Protein Product. Rockville, MD: Food and Drug Administration; 2012.

87. Heinemann L. Biosimilar insulins. Expert Opin Biol Ther. 2012;12: 1009-1016

88. Kramer I, Sauer T. The new world of biosimilars: what diabetologists need to know about biosimilar insulins. Br J Diabetes Vasc Dis. 2010;10:163-171.

89. Drucker DJ. Biologic actions and therapeutic potential of the proglucagon-derived peptides. Nat Endocrinol Metab. 2005;1:22-31.

90. Peters A. Incretin-based therapies: review of current clinical trial data. Am J Med. 2010;123(Suppl):S28-S37. 
91. DeFronzo RA, Ratner RE, Han J. Effects of Exenatide (exendin-4) on glycemic control and weight over 30 weeks in metformin-treated patients with type 2 diabetes. Diabetes Care. 2005;28:1092-1100.

92. Buse JB, Henry RR, Han J Kim DD, Fineman MS, Baron AD; Exenatide-113 Clinical Study Group. Effects of exenatide on glycemic control over 30 weeks in sulfonylurea-treated patients with type 2 diabetes. Diabetes Care. 2005;27:2628-2635.

93. Blevins T, Pullman J, Malloy J, et al. DURATION-5: exenatide once weekly resulted in greater improvements in glycemic control compared with exenatide twice daily in patients with type 2 diabetes. J Clin Endocrinol Metab. 2011;96(5):1301-1310.

94. Derosa G, Maffioli P. GLP-1 agonists exenatide and liraglutide: a review about their safety and efficacy. Curr Clin Pharmacol. 2012;7: 214-228.

95. Peyrot M, Rubin RR, Polonsky WH, Best JH. Patient reported outcomes in adults with type 2 diabetes on basal insulin randomized to addition of mealtime pramlintide or rapid-acting insulin analogs. Curr Med Res Opin. 2010;26:1047-1054.

96. Riddle M, Pencek R, Charenkavanich S, Lutz K, Wilhelm K, Porter L. Randomized comparison of pramlintide or mealtime insulin added to basal insulin treatment for patients with type 2 diabetes. Diabetes Care. 2009;32:1577-1582.

97. NIH conference. Gastrointestinal surgery for severe obesity. Consensus development conference panel. Ann Intern Med. 1991;115:956-961.

98. Polyzogopoulou EV, Kalfarentzos F, Vagenakis AG, Alexandrides TK Restoration of euglycemia and normal acute insulin response to glucose in obese subjects with type 2 diabetes following bariatric surgery. Diabetes. 2003;52:1098-1103.
99. Sjöström L, Peltonen M, Jacobson P, et al. Association of bariatric surgery with long-term remission of type 2 diabetes and with microvascular and macrovascular complications. JAMA. 2014;311(22): 2297-2304.

100. Yi P, Park JS, Melton AD. Betatrophin: a hormone that controls pancreatic $\beta$ cell proliferation. Cell. 2013;153(4):747-758.

101. Saisho Y, Butler AE, Manesso E, Butler PC. $\beta$-cell mass and turnover in humans: effects of obesity and aging. Diabetes Care. 2013;36(1): $111-117$

102. Brennan AM, Mantzoros CS. Drug Insight: the role of leptin in human physiology and pathophysiology - emerging clinical applications. Nat Clin Pract Endocrinol Metab. 2006;6:318-327.

103. Cummings BP. Leptin therapy in type 2 diabetes. Diabetes Obes Metab. 2013;15(7):607-612.

104. Coppari R, Bjørbæk C. Leptin revisited: its mechanism of action and potential for treating diabetes. Nat Rev Drug Discov. 2012;11(9): 692-708

105. Zorrilla EP, Iwasaki S, Moss JA, et al. Vaccination against weight gain. Proc Natl Acad Sci U S A. 2006;103(35):13226-13231.

106. Chen CY, Fujimiya M, Laviano A, Chang FY, Lin HC, Lee SD. Modulation of ingestive behavior and gastrointestinal motility by ghrelin in diabetic animals and humans. J Chin Med Assoc. 2010;73(5): 225-229.

107. Russell SJ, El-Khatib FH, Nathan DM, Magyar KL, Jiang J, Damiano ER. Blood glucose control in type 1 diabetes with a bihormonal bionic endocrine pancreas. Diabetes Care. 2012;35(11):2148-2155.

108. Pagliuca FW, Millman JR, Gürtler M, et al. In vitro generation of functional human pancreatic $\beta$ cells. Cell. 2014;159(2):428-439.
Research and Reports in Endocrine Disorders

\section{Publish your work in this journal}

Research and Reports in Endocrine Disorders is an international, peerreviewed, open access journal publishing original research, reports, reviews and commentaries on all areas of endocrinology, endocrine disorders and therapeutic interventions. The manuscript management system is completely online and includes a very quick and fair

\section{Dovepress}

peer-review system. Visit http://www.dovepress.com/testimonials.php to read real quotes from published authors. 